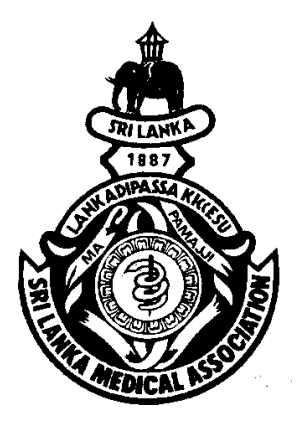

All communications

should be addressed to

The Editors, CMJ

Editors Emeritus

Chris G Uragoda MD, FRCP

Colvin Goonaratna FRCP, PhD

Editors

Janaka de Silva DPhil, FRCP

Anuruddha Abeygunasekera MS, FRCS

Assistant Editors

Vasanthy Arasaratnam MSc, PhD

D N Atukorala MD, FRCP

Varuni De Silva MBBS, MD

S A S Goonewardena MS, FRCS

Malik Goonewardene MS, FRCOG

Renuka Jayatissa MD, MSc

Neelika Malavige MRCP, DPhil

A Pathmeswaran MBBS, MD

B J C Perera MD, FRCPCH

Channa D Ranasinha DTM\&H, FRCP

Udaya K Ranawaka MD, FRCP

Shalini Sri Ranganathan MD, PhD

D N Samarasekera MS, MD, FRCS

Manouri Senanayake MD, FRCP

Kamani H Tennekoon MBBS, PhD

International Advisory Board

Kamran Abbasi MBChB, MRCP

London, UK

Raja Bandaranayake FRACS, PhD

Sydney, Australia

Peush Sahni MS, PhD

New Delhi, India

R K Tandon MD, PhD

New Delhi, India

Zulfiqar Ahmed Bhutta FRCPCH, PhD

Karachi, Pakistan

Continued overleaf
THE CEYLON

MEDICAL JOURNAL

Established 1887

The Official Publication of the

Sri Lanka Medical Association

Volume 57, No.3, September 2012

Quarterly ISSN 0009-0875

\section{Pathogenesis of severe dengue infection}

Dengue viral infections have increased dramatically over past three decades, and are currently the mosquito borne infections with the highest mortality in Sri Lanka. As a result of the high disease burden, dengue has been declared a priority infection by the WHO, UNICEF and World Bank [1]. Although the Sri Lankan population has been exposed to the virus for decades, severe forms of dengue infection [dengue haemorrhagic fever and dengue shock syndrome (DHF/DSS)] were rare until 1989. Since then Sri Lanka has been experiencing yearly epidemics of DHF, with the number of cases rising each year. However, case fatality has remained $<1 \%$ in recent years, both in Sri Lanka and the region as a whole, probably due to better management practices [1].

Dengue can occur due to infection with any of the four dengue virus (DV) serotypes (DEN-1-4), which are closely related. Infection can result in asymptomatic infection, undifferentiated fever, dengue fever, DHF/DSS or dengue infection complicated with organ failure $[1,2]$. The key question is why only some individuals develop severe forms of the infection, and others have asymptomatic or mild clinical disease. Although severe manifestations are thought to result from a complex interplay between the virus, host genetic makeup and host immune factors, many questions regarding factors that lead to severe disease and the pathophysiology of dengue infection itself remain unanswered. In addition, the clinical severity of dengue infections appears to differ in adults and children and also in altered physiological states such as in pregnancy [3-5]. For instance, children have been shown to be more predisposed to develop shock during dengue infections, while other complications such as bleeding and liver involvement have been shown to be commoner in adults $[4,5]$.

Initial infection with a particular serotype is known as a primary infection, which is usually asymptomatic or results in mild disease manifestations [6]. Subsequent infection with other serotypes (secondary dengue infections) may lead to severe disease [6]. Most people who are infected have silent infections, but $0.18-1 \%$ of primary infections and $2-9 \%$ of secondary infections manifest as DHF/DSS [6]. Certain DV strains are more virulent than others, and apart from host factors, frequency of severe infections may vary depending on the circulating virus genotype or serotype $[7,8]$.

\section{Pathogenesis of severe disease}

Following the bite of an infected mosquito the DV initially infects langerhans cells in the epidermis and keratinocytes. Subsequently it infects many other cells, such as, monocytes, dendritic cells (DCs), macrophages, endothelial cells (EC) and hepatocytes [9, 10]. Infected monocytes and DCs produce massive amounts of proinflammatory cytokines and chemokines 
Samiran Nundy FRCS, FRCP

New Delhi, India

N Medappa MD

New Delhi, India

Jane Smith BA, MSc

London, UK

Anita KM Zaidi MMBS, SM

Karachi, Pakistan

David Warrell MD, FRCP

Oxford, UK

Advisory Board for Statistics and Epidemiology

Lalini Rajapakse MD, MSc

Kumudu Wijewardene MBBS, MD

A Pathmeswaran MBBS, MD

\section{Published by}

The Sri Lanka Medical

Association

Wijerama House

6, Wijerama Mawatha

Colombo 7

Sri Lanka

Tel: +94 112693324

Fax: +94 112698802

Internet home page

http://www.sljol.info/index.php/CMJ/index

e-mail: office@cmj.slma.lk

\section{Printed by}

Ananda Press

82/5, Sir Ratnajothi Saravanamuttu

Mawatha, Colombo 13

Sri Lanka

Tel: +94 112435975

Fax: +94 112385039

e-mail: anpress@sItnet.lk

\section{For advertising}

Please contact:

Mr. Anthony

Saatchi \& Saatchi

79, C W W Kannangara Mawatha

Colombo 7

Tel: +94 112671026 +94 772514858

e-mail: anthony_sinniha@saatchisl.com

(C) The Ceylon

Medical Journal

This journal is indexed by BIOSIS, SCOPUS, EMBASE, CABI, and Index Medicus/Medline which, along with activated $\mathrm{T}$ cells, are thought to cause endothelial dysfunction $[11,12]$. Endothelial dysfunction leads to increased vascular permeability which is the hallmark of DHF; it causes vascular leak, collection of fluid in pleural and peritoneal cavities and shock [13]. ECs are activated during dengue infections, and also contribute to the immune responses that induce vascular permeability [13]. As increased capillary permeability and vascular leakage are reversible, they were thought to result from EC dysfunction rather than EC injury [10]. However, autopsy studies on victims of fatal dengue shock syndrome have shown selective apoptosis in ECs of the intestinal and pulmonary vasculature [14]. Although the mechanisms for apoptosis are not clearly understood, DV-NS1 protein specific antibodies have been shown to induce EC apoptosis [15]. Therefore, increased vascular permeability and fluid leakage may not be solely due to EC dysfunction in all patients. In some it could be the result of EC damage leading to more severe disease.

\section{Organ involvement}

The liver is commonly involved in dengue infections, and acute liver failure (ALF) has also been reported [16-18]. Autopsy studies carried out in patients with fatal hepatitis associated with dengue infection have shown midzonal hepatocyte necrosis, macrovascular steatosis and councilman bodies, with little inflammation [10,19]. Although most patients with ALF associated with dengue infection also have other complications, such as, fluid leakage and shock, ALF can occur in the absence of shock [20]. Dengue associated ALF has a high mortality due to complications such as encephalopathy, severe bleeding, renal failure and metabolic acidosis [18, 20]. Direct hepatocyte damage by the virus $[9,10]$, immune factors and apoptosis of cells due to oxidative stress, have all been suggested as possible mechanisms for liver cell damage [21].

Varying forms of central nervous system (CNS) involvement have been reported in dengue infections; they include encephalopathy, encephalitis and meningoencephalitis [22]. Fluid extravasation, cerebral oedema, ALF, renal failure and electrolyte imbalance are thought to contribute to encephalopathy associated with dengue $[18,22]$. The DV can be neurovirulent, and has been isolated from the CSF in patients with encephalitis, in the absence of fluid leakage and other clinical features of severe dengue [23,24].

Myocarditis during dengue infections is associated with cardiac arrhythmias, reduced left ventricular ejection fraction, $\mathrm{T}$ wave inversions, and elevated troponin I and CPK-MB levels reflecting myocardial damage [25-27]. Cardiac involvement is thought to be either immune mediated or due to direct infection of myocytes [26]. A few autopsy studies in patients with myocarditis have demonstrated presence of virus antigen within cells of the myocardium [27] associated with a mild inflammatory cell infiltrate [25, 27].

\section{Immunopathogenesis}

Host genetic factors play a role in the development of severe manifestations in dengue infections. Certain HLA- class I such as HLA-A*24, HLA-A*53, HLA-A*203, HLA-B*51 and class II alleles [28, 29], polymorphisms in the tumour necrosis factor alpha (TNF- $\alpha)$, Vitamin D receptor [30], CTLA-4, and transforming growth factor $\beta$ (TGF- $\beta$ ) [31] have been shown to be associated with development of DHF/DSS [10]. In Sri Lankan patients, HLA-A*31 and DRB $1 * 08$ are significantly associated with susceptibility to DSS [32]. However, careful assessment of other host genetic factors that may predispose individuals to severe dengue is necessary to further our understanding of the pathogenesis of dengue infections. 
There is evidence that both cross reactive $\mathrm{T}$ cells and antibodies contribute to pathogenesis in secondary dengue infections. Poorly neutralizing and disease enhancing antibodies are thought to increase infection of cells such as macrophages and DCs [10]. As more and more cells are infected larger quantities of proinflammatory cytokines are secreted resulting in increasing endothelial dysfunction. Although it is widely believed that immune factors are solely responsible for severe clinical disease, patients with severe forms of dengue have higher viral loads and prolonged viraemia [33]. Therefore, it appears that severe dengue is associated with impaired viral control, and indeed, immunosuppressive cytokines such as IL-10 are significantly elevated in patients with DSS compared to those who do not develop shock [34]. T cell responses generated during acute DV infection are highly cross reactive. Cross reactive DV-specific T cells have suboptimal degranulation capacity, but secrete high levels of cytokines [35]. Therefore, reduced or suboptimal antiviral responses may also to contribute to disease pathogenesis [36].

\section{Treatment and prevention}

Currently, there are no specific drugs for treatment of dengue infection. Management of DHF/DSS is currently based on careful monitoring and early detection of complications, and appropriate intravenous fluid therapy [1]. In addition, organ failure should be treated on its own merits. There are ongoing efforts to develop specific antiviral drugs and other treatment modalities that may improve the outcome of dengue infection [37] and its associated organ specific complications, such as, the use of $\mathrm{N}$-acetylcysteine in ALF [38, 39]. More research, including randomised clinical trials, is required to replace much of the dogma with evidence based management practices.

The ultimate solution would be to develop a safe and effective vaccine to prevent dengue. However, development of a vaccine has been extremely challenging. The main obstacle is the lack of data regarding correlates of a protective immune response [40]. A dengue vaccine should provide lifelong immunity for all four DV serotypes. Before vaccine programmes can be initiated critical issues, such as, the impact of poor antibody responses to the vaccine in causing disease enhancement, effect of possible waning of antibody responses with time, possible induction of disease enhancing and poorly neutralising antibody responses, induction of cross reactive $\mathrm{T}$ cell responses with the vaccine, and finally, the impact of large scale vaccination on evolution of the wild type $\mathrm{DV}$, need to be resolved. Many institutions have taken up this challenge, and currently there are several dengue vaccine candidates undergoing phase 1a to phase 3 clinical trials [40]. Until such time a vaccine becomes available, prevention will continue to depend on vector control.

\section{References}

1. Comprehensive Guidelines for Prevention and Control of Dengue Fever and Dengue Haemorrhagic Fever. World Health Organization, 2011.

2. Malavige GN, Fernando S, Fernando DJ, Seneviratne SL. Dengue viral infections. Postgraduate Medical Journal 2004; 80: $588-601$.

3. Waduge R, Malavige GN, Pradeepan M, et al. Dengue infections during pregnancy: a case series from Sri Lanka and review of the literature. Journal of Clinical Virology 2006; 37: 27-33.

4. Dinh The T, Le Thi Thu T, Nguyen Minh D, et al. Clinical features of dengue in a large vietnamese cohort: intrinsically lower platelet counts and greater risk for bleeding in adults than children. PLoS Neglected Tropical Diseases 2012; 6: e1679.

5. Balasubramanian S, Ramachandran B, Amperayani S. Dengue viral infection in children: a perspective. Archives of Disease in Childhood 2012 (in press).

6. Mathew A, Rothman AL. Understanding the contribution of cellular immunity to dengue disease pathogenesis. Immunological Reviews 2008; 225: 300-13.

7. Messer WB, Gubler DJ, Harris E, Sivananthan K, de Silva AM. Emergence and global spread of a dengue serotype 3, subtype III virus. Emerging Infectious Diseases 2003; 9: 800-9.

8. Kyle J L, Harris E. Global spread and persistence of dengue. Annual Review of Microbiology 2008; 62: 71-92.

9. Diamond MS, Edgil D, Roberts TG, Lu B, Harris E. Infection of human cells by dengue virus is modulated by different cell types and viral strains. Journal of Virology 2000; 74: 7814-23.

10. Martina BE, Koraka P, Osterhaus AD. Dengue virus pathogenesis: an integrated view. Clinical Microbiology Reviews 2009; 22: 564-81.

11. Brown MG, Hermann LL, Issekutz AC, et al. Dengue virus infection of mast cells triggers endothelial cell activation. Journal of Virology 2011; 85: 1145-50.

12. Simmons CP, Dong T, Chau NV, et al. Early T-cell responses to dengue virus epitopes in Vietnamese adults with secondary dengue virus infections. Journal of Virology 2005; 79: 5665-75.

13. Dalrymple NA, Mackow ER. Endothelial cells elicit immune-enhancing responses to dengue virus infection. Journal of Virology 2012; 86: 6408-15.

14. Limonta D, Capo V, Torres G, Perez AB, Guzman MG. Apoptosis in tissues from fatal dengue shock syndrome. Journal of Clinical Virology 2007; 40: 50-4.

15. Lin CF, Lei HY, Shiau AL, et al. Antibodies from dengue patient sera cross-react with endothelial cells and induce damage. Journal of Medical Virology 2003; 69: 82-90.

16. Wichmann $\mathrm{O}$, Hongsiriwon $\mathrm{S}$, Bowonwatanuwong $\mathrm{C}$, et al. Risk factors and clinical features associated with severe dengue infection in adults and children during the 2001 epidemic in Chonburi, Thailand. Tropical Medical International Health 2004; 9: 1022-9. 
17. Seneviratne SL, Malavige GN, de Silva HJ. Pathogenesis of liver involvement during dengue viral infections. Transactions of the Royal Society of Tropical Medicine and Hygiene 2006; 100: 608-14.

18. Malavige GN, Ranatunga PK, Jayaratne SD, et al. Dengue viral infections as a cause of encephalopathy. Indian Journal of Medical Microbiology 2007; 25: 143-5.

19. Guzman MG, Alvarez M, Rodriguez R, et al. Fatal dengue hemorrhagic fever in Cuba, 1997. International Journal of Infectious Diseases 1999; 3: 130-5.

20. Trung DT, Thao le TT, Hien TT, et al. Liver involvement associated with dengue infection in adults in Vietnam. The American Journal of Tropical Medicine and Hygiene 2010; 83: $774-80$.

21. Gil L, Martinez G, Tapanes R, et al. Oxidative stress in adult dengue patients. The American Journal of Tropical Medicine and Hygiene 2004; 71: 652-7.

22. Araujo FM, Araujo MS, Nogueira RM, et al. Central nervous system involvement in dengue: a study in fatal cases from a dengue endemic area. Neurology 2012; 78: 736-42.

23. Lum LC, Lam SK, Choy YS, George R, Harun F. Dengue encephalitis: a true entity? The American Journal of Tropical Medicine and Hygiene 1996; 54: 256-9.

24. Solomon T, Dung NM, Vaughn DW, et al. Neurological manifestations of dengue infection. Lancet 2000; 355: 1053 9.

25. Weerakoon $\mathrm{KG}$, Kularatne SA, Edussuriya $\mathrm{DH}$, et al. Histopathological diagnosis of myocarditis in a dengue outbreak in Sri Lanka, 2009. BMC Research Notes 2011; 4: 268

26. Lee IK, Lee WH, Liu JW, Yang KD. Acute myocarditis in dengue hemorrhagic fever: a case report and review of cardiac complications in dengue-affected patients. International Journal Infectious Diseases 2010; 14: e919-22.

27. Salgado DM, Eltit JM, Mansfield K, et al. Heart and skeletal muscle are targets of dengue virus infection. The Pediatric Infectious Disease Journal 2010; 29: 238-42.

28. Appanna R, Ponnampalavanar S, Lum Chai See L, Sekaran SD. Susceptible and protective HLA class 1 alleles against dengue fever and dengue hemorrhagic fever patients in a Malaysian population. PloS One 2010; 5: e13029.

29. Stephens HA, Klaythong R, Sirikong M, et al. HLA-A and -B allele associations with secondary dengue virus infections correlate with disease severity and the infecting viral serotype in ethnic Thais. Tissue Antigens 2002; 60: 30918 .

30. Loke H, Bethell D, Phuong CX, et al. Susceptibility to dengue hemorrhagic fever in vietnam: evidence of an association with variation in the vitamin $\mathrm{d}$ receptor and $\mathrm{Fc}$ gamma receptor IIa genes. The American Journal of Tropical Medicine and Hygiene 2002; 67: 102-6.

31. Chen RF, Wang L, Cheng JT, et al. Combination of CTLA4 and TGFbetal gene polymorphisms associated with dengue hemorrhagic fever and virus load in a dengue- 2 outbreak. Clinical Immunology 2009; 131: 404-9.

32. Malavige GN, Rostron T, Rohanachandra LT, Jayaratne SD, Fernando N, De Silva AD, Liyanage M, Ogg GS. HLA class I and class II associations in dengue viral infections in a Sri Lankan population. PloS One: e20581.

33. Wang WK, Chen HL, Yang CF, et al. Slower rates of clearance of viral load and virus-containing immune complexes in patients with dengue hemorrhagic fever. Clinical Infect Dis 2006; 43: 1023-30.

34. Chen LC, Lei HY, Liu CC, et al. Correlation of serum levels of macrophage migration inhibitory factor with disease severity and clinical outcome in dengue patients. The American Journal of Tropical Medicine and Hygiene 2006; 74: $142-7$.

35. Mongkolsapaya J, Duangchinda T, Dejnirattisai W, et al. T cell responses in dengue hemorrhagic fever: are cross-reactive $\mathrm{T}$ cells suboptimal? Journal of Immunology 2006; 176: 3821-9.

36. Dong $\mathrm{T}$, Moran $\mathrm{E}$, Vinh Chau N, et al. High proinflammatory cytokine secretion and loss of high avidity cross-reactive cytotoxic T-cells during the course of secondary dengue virus infection. PloS One 2007; 2: e1 192.

37. Simmons CP, Farrar JJ, Nguyen VV, Wills B. Dengue. The New England Journal of Medicine 2012; 366: 1423-32.

38. Kumarasena RS, Mananjala Senanayake S, Sivaraman K, et al. Intravenous $\mathrm{N}$-acetylcysteine in dengue-associated acute liver failure. Hepatology International 4: 533-4.

39. Lim G, Lee JH. N-acetylcysteine in children with dengueassociated liver failure: a case report. Journal of Tropical Pediatrics 2012 (in press).

40. Thomas SJ, Endy TP. Critical issues in dengue vaccine development. Current Opinion in Infectious Diseases 2011; 24: $442-50$

G N Malavige, Department of Microbiology, Faculty of Medical Sciences, University of Sri Jayewardenepura, Nugegoda, Sri Lanka, and G Ogg, MRC Human Immunology Unit, Weatherall Institute of Molecular Medicine, University of Oxford, UK.

Correspondence: GNM, e-mail: <neelikamalavige@gmail.com>. Competing interests: none declared. 